\title{
PPGLinC 10
}

\section{O PORTUGUÊS LÍNGUA ESTRANGEIRA (PLE) / SEGUNDA LÍNGUA (PL2) NA UFBA: INSTITUCIONALIZAÇÃO, DESAFIOS E PROSPECÇÕES}

\author{
PORTUGUESE FOREIGN LANGUAGE (PLE) / SECOND \\ LANGUAGE (PL2) IN UFBA: INSTITUTIONALIZATION, \\ CHALLENGES AND PROSPECTIONS
}

\author{
Lucas Rodrigues ${ }^{1}$ \\ ICR Brasil/Instituto BrazilLink \\ Sara Oliveira da Cruz ${ }^{2}$ \\ Instituto Federal da Bahia \\ Edleise Mendes ${ }^{3}$ \\ Universidade Federal da Bahia
}

\begin{abstract}
Resumo: Este artigo tem como objetivo refletir sobre a institucionalização da área de português língua estrangeira/segunda língua (PLE-PL2) na UFBA. A partir de um breve histórico (MENDES; 2018, 2020), discutimos as características gerais da Licenciatura em PLE e os princípios que orientam a formação de seus professores. A partir desse cenário, apresentamos os exemplos de duas pesquisas concluídas no Programa de Pós-Graduação em Língua e Cultura (PPGLinC) da UFBA (CRUZ, 2019; RODRIGUES, 2019), que analisam, entre outros aspectos, o desenvolvimento de projetos institucionais implementados pela Universidade, como o PROEMPLE e o NUPEL. Os resultados das pesquisas apontam a necessidade de aprimoramento dos projetos institucionais na área, mas destacam a importância dessas ações promovidas pela UFBA, como meio de fortalecimento do ensino e da formação de professores, bem como da internacionalização universitária.
\end{abstract}

Palavras-Chave: Português Língua Estrangeira/Segunda Língua (PLE/PL2); Institucionalização; Universidade Federal da Bahia.

\footnotetext{
1 lucasrodriguesufba@gmail.com

2 oliveira.kid@gmail.com

3 edleise.mendes@gmail.com
} 
Abstract: This article aims to reflect on the institutionalization of the area of Portuguese foreign language/second language (PLE-PL2) at (UFBA). We have discussed the general characteristics of the PLE graduation and the principles that guide the training of its teachers based on a brief history (MENDES; 2018, 2020). Thus, we present two examples of completed studies in the Programa de Pós-Graduação em Lingua e Cultura (PPGLinC) at UFBA (CRUZ, 2019; RODRIGUES, 2019), which analyze, among other aspects, the development of institutional projects implemented by the University, such as PROEMPLE and NUPEL. The results of this research point to the need to improve institutional projects in the area, but they also highlight the importance of these actions, as a means of strengthening the teaching and training of teachers, as well as university internationalization.

Keywords: Portuguese Foreign Language / Second Language (PLE/PL2); Institutionalization; Federal University of Bahia.

\section{INTRODUÇÃO}

Há pouco mais de uma década, em diferentes contextos de ensino no mundo, a área de Português Língua Estrangeira (PLE)/Segunda Língua (PL2) não era suficientemente institucionalizada e qualquer pessoa "falante de português" poderia ensinar a língua. No entanto, com o crescimento da demanda pelo seu ensino, a criação de diversas comunidades e associações profissionais de docentes da área, assim como a implementação de disciplinas e de cursos de PLE/PL2 nas universidades e faculdades, públicas e privadas, essa realidade mudou sensivelmente. Hoje, para atuar na área é exigida do(a) professor(a) uma formação específica em língua portuguesa e o conhecimento de princípios e práticas pedagógicas para o ensino de LE/L2. Não basta, então, uma formação genérica em Letras, sem que haja uma orientação voltada para a educação em língua estrangeira, que difere, em muitos aspectos, da educação em língua materna.

Com a crescente profissionalização do campo, as instituições de ensino, de diferentes instâncias, têm observado a contratação de professore(a)s com formação na área e, na medida do possível, com experiência de ensino. Mas a demanda tem sido muito maior do que a nossa capacidade de formar novo(a)s professore(a)s, isso incluindo-se os dois principais polos formadores, Portugal e Brasil, e ainda os cursos de formação em Moçambique e Angola, apenas para citar 
aqueles que fazem parte da Comunidade de Países de Língua Portuguesa (CPLP), sem nos ater às dezenas de cursos já atuantes em diferentes partes do mundo, na Europa, na América Latina, na América do Norte e, mais recentemente, na Ásia. (MENDES, 2018)

A grande demanda por profissionais dessa área tem forçado a criação de novos cursos de formação inicial, em nível de graduação, para professore(a)s de português como língua estrangeira no Brasil. Há, atualmente, o movimento de muitas universidades brasileiras planejando o oferecimento de cursos de licenciatura plena em PLE, como a Universidade Federal do Rio Grande do Sul (UFRGS), a Universidade Federal de Minas Gerais (UFMG), a Universidade Federal da Paraíba (UFPB), a Universidade Federal do Rio Grande do Norte (UFRN) e a Universidade Federal do Ceará (UFCE), somente para citar algumas. No entanto, até o momento, apenas quatro universidades mantêm cursos para a formação de professore(a)s dessa área, aqui citados em ordem cronológica do seu surgimento: 1) Universidade de Brasília - UnB (Português Segunda Língua); b) Universidade Federal da Bahia - UFBA (Português Língua Estrangeira / Segunda Língua); c) Universidade Estadual de Campinas - UNICAMP (Português Língua Estrangeira); d) Universidade da Integração Latino-Americana - UNILA (Português Língua Adicional).

Dentre elas, o curso da Universidade de Brasília (UnB), pioneiro no Brasil, especializou-se em formar professores para atuarem em contexto de segunda língua, sobretudo no Brasil, para atender à comunidade internacional que mora e atua em organizações e representações diplomáticas, bem como à comunidade de surdos brasileira, mas também a outros contextos no exterior, embora com menor ênfase. Criado em 1998, o curso da UnB colocou no mercado as primeiras levas de professores de PLS (Português Língua Segunda) com formação específica na área. A UFBA foi, portanto, a segunda instituição brasileira a 
implementar a licenciatura em português como língua estrangeira/segunda língua, atuando desde 2005.

Este artigo, desse modo, tem como objetivo principal refletir sobre a área de português língua estrangeira / segunda língua (PLE/PL2) em contexto institucional na Universidade Federal da Bahia (UFBA), especialmente a Licenciatura na área, iniciada no ano de 2005. A partir de um breve histórico sobre a área na UFBA, discutiremos as características gerais do curso e sua ancoragem em princípios voltados para uma formação culturalmente sensível de seus professores, problematizando os desafios institucionais para o desenvolvimento profissional de docentes capazes de enfrentar a diversidade e a complexidade do mundo contemporâneo. A partir desse cenário, discutiremos o avanço das pesquisas em nível de pós-graduação, trazendo como exemplos dois trabalhos recentemente concluídos e que discutem, de modo direto, a institucionalização da área na UFBA. Não se pretende realizar um mapeamento das pesquisas na área, de modo mais amplo, visto que tal análise foge do escopo deste trabalho, mas analisar as investigações que se dedicaram a discutir projetos institucionais da UFBA, seus desafios e prospecções, dentro do quadro das políticas desenvolvidas pela Universidade como meio de fomento a uma educação linguística democrática e inclusiva.

\section{A ÁREA DE PLE/PL2 NA UFBA: FORMANDO PROFESSORE(A)S PARA A DIVERSIDADE}

O Curso de Licenciatura em Português Língua Estrangeira/Segunda Língua da (UFBA) foi criado em 2005 e teve, em sua primeira constituição, uma formação em dupla habilitação, ou seja, preparava o egresso para o ensino de língua materna e também de língua estrangeira (Licenciatura em Letras Vernáculas e Língua Estrangeira Moderna - Português Língua Estrangeira). Com as mudanças empreendidas pelo Ministério da Educação, sobretudo pela 
determinação imposta pela Resolução CNE/CP no.1/2011, que previa um aumento da carga horária das Licenciaturas em Letras com dupla habilitação para o mínimo de 3.600 horas, muitas instituições de ensino superior foram forçadas a reformular os seus cursos. Esse foi o impulso para que a Comissão de Reforma Curricular decidisse pela extinção das habilitações duplas, entre outros motivos, pela grande quantidade de evasão desses cursos por parte dos alunos, devido à carga horária mais pesada e ao retardo na integralização do curso. (MENDES, 2020).

Assim, em 2012, o curso da UFBA foi totalmente reformulado, e passou a ser uma Licenciatura em Língua Estrangeira - Português Língua Estrangeira/Segunda Língua. Tal reforma alterou significativamente a organização curricular e os conteúdos do curso, dando uma "nova cara" a essa Licenciatura, que já apresentava uma grande demanda de alunos e crescia enormemente, sem que tivéssemos corpo docente preparado para atender a essa demanda emergente. Em sua nova formulação, o projeto do curso aponta:

\begin{abstract}
A Licenciatura em Letras com ênfase em Português como Língua Estrangeira objetiva formar profissionais capacitados para o ensino de português para falantes de outras línguas, em variados contextos nos quais pode ser desenvolvido, como língua estrangeira ou segunda língua, preparando-os, também, para compreender a dimensão multicultural das sociedades contemporâneas e para atuar como agentes promotores de uma educação linguística intercultural, capaz de promover e incentivar a projeção do português brasileiro como língua de cultura. ${ }^{4}$
\end{abstract}

Grande ênfase é dada no curso $^{5}$ à preparação do professor para desenvolver um corpo de conhecimentos que inclua não apenas o domínio dos

\footnotetext{
4 Universidade Federal da Bahia. Projeto de Reformulação Curricular do Curso de Letras, 2012, p. 35 (Acesso restrito).

5 Em Mendes (2020), a autora discute as características desse curso e sua ancoragem em princípios voltados para uma formação culturalmente sensível de seus professores. Nesse texto, ela apresenta com mais riqueza de detalhes as bases teórico-metodológicas que orientam a formação dos professores/futuros professores ao longo do curso de graduação e o que é esperado
} 
conteúdos específicos da língua, objeto de seu ensino, mas também uma formação crítica e ancorada na compreensão da diversidade e da necessidade de desenvolvimento de práticas educacionais culturalmente sensíveis aos sujeitos envolvidos no processo de ensino e aprendizagem. Além disso, o(a) professor(a) deve ser preparado(a) para atuar, antes de tudo, como um agente de interculturalidade, bem como agente político de promoção e de projeção da língua portuguesa no mundo, a qual se apresenta como uma das línguas que mais cresce no século XXI, como afirma Mendes (2019, p. 38):

O português, uma língua presente em quatro continentes, tem ultimamente angariado a atenção de governos e instituições no âmbito do desenvolvimento de ações que valorizem esse capital linguístico, sobretudo como ponte de acesso a outros capitais importantes, como o econômico e o político, no cenário global de reordenamento dos interesses e necessidades de países e governos. Esse movimento tem sido perceptível em variados contextos e situações, sobretudo nos diferentes discursos que emanam da comunidade acadêmica, da sociedade civil e também dos governos. [...].

Em nível de pós-graduação, muitas universidades no Brasil mantêm em suas linhas de investigação temas relacionados ao ensino e à formação de professore(a)s de PLE/PL2, ampliando, de modo bastante significativo, as pesquisas e contribuindo para fomentar o interesse de novo(a)s estudantes, professore(a)s e investigadore(a)s pela área. Hoje é possível encontrar trabalhos em nível de mestrado e de doutorado desenvolvidos na maior parte das universidades brasileiras, e basta uma breve pesquisa no banco de teses e dissertações da Capes $^{6}$ para se constatar a ampliação e a representatividade da pesquisa dessa área no grande campo dos estudos da linguagem.

Na UFBA, as pesquisas em PLE/PL2 têm sido desenvolvidas no Programa de Pós-Graduação em Língua e Cultura (PPGLinC), na área Linguagem e Interação e na Linha de Linguística Aplicada. Desde a criação da LPLE-UFBA, e até bem

de um graduando/graduanda ao final do Curso de Licenciatura em Português Língua Estrangeira/Segunda Língua da UFBA.

6 Ver: http://bancodeteses.capes.gov.br/. 
antes dela, já havia o interesse de pesquisadores pela área, embora essa conte com poucos professore(a)s orientadore(a)s no Programa. Até o momento, por exemplo, apesar do corpo docente restrito, já contabilizamos mais de quarenta trabalhos defendidos, entre dissertações de mestrado e teses de doutorado ${ }^{7}$.

A partir desse cenário institucional, reforçamos a ideia de que ao formarmos professore(a)s de PLE/PL2, devemos lidar com diferentes elementos que compõem o conjunto de práticas pedagógicas, de procedimentos e de ações que caracterizam uma abordagem de ensino para LE/L2, como o planejamento de cursos, a seleção, avaliação e elaboração de materiais didáticos, a avaliação de aprendizagem e a avaliação de proficiência, entre outros elementos que compõem o processo de ensinar e aprender uma língua. Mas além disso, uma formação adequada deve capacitar o(a) professore(a)s em formação para construir estratégias e criar ambientes propícios para que o processo de ensino/aprendizagem de uma nova língua-cultura ${ }^{8}$ seja um projeto voltado para a criação de um diálogo entre as culturas ali em interação. Além disso, uma formação adequada e que prepare o(a)s professor(a) de LE/L2 para enfrentar os desafios dos contextos diversificados, linguísticos e culturais, nos quais atua, deve dar condições ao(à) estudante em formação, de conhecer a evolução das ideias linguísticas, de ter contato com teorias e práticas diversificadas e refletir sobre os objetivos que estão em jogo quando ele/ela vai desenvolver pesquisa ou ensinar. Deve ser também um processo de formação capaz de prepará-lo(a) para decidir, com autonomia e consciência crítica, que representações de língua e de linguagem estarão na base de suas ações. (MENDES, 2012a; 2018).

\footnotetext{
7 Ver: http://bancodeteses.capes.gov.br/.

8 A língua como cultura e lugar de interação. A visão de língua/linguagem como instância de interação e inserção do sujeito no mundo, e que inclui uma rede complexa de fatores linguísticos e extralinguísticos. Língua, que mais do que parte da dimensão cultural, é a própria cultura, se confundindo com ela. A essa língua que não é uma abstração teórica e que não possui existência fora do contexto social de uso pelos seus falantes, denominaremos de língua-cultura (MENDES, 2008).
} 


\section{O PORTUGUÊS PARA ESTRANGEIROS NO PROFICI: PERCEPÇÕES DE APRENDIZAGEM DO(A)S ALUNO(A)S PRÉ- PEC-G SOBRE A PEDAGOGIA DE PROJETOS}

Um exemplo de pesquisa desenvolvida no Programa de Pós-Graduação em Língua e Cultura (PPGLINC) da Universidade Federal da Bahia (UFBA) foi a dissertação de mestrado de Rodrigues (2019)9. Nesse trabalho, o pesquisador se debruçou sobre as percepções de aprendizagem do(a)s aluno(a)s sobre a pedagogia de projetos, abordagem adotada em um Programa institucional que oferece curso de português para estrangeiros na UFBA. A pesquisa teve os seguintes objetivos: identificar quais percepções de aprendizagem o(a)s aluno(a)s tiveram a respeito do seu aprendizado com a pedagogia de projetos; confrontar tais percepções com os benefícios esperados por aprendizes dessa abordagem; além de propor contribuições para o aprimoramento da proposta metodológica do Programa.

A pesquisa foi realizada no PROFICI (Programa de Proficiência para Estudantes e Servidores da UFBA), que é uma das iniciativas da Universidade na área de português como língua estrangeira, doravante PLE. Em um contexto mais amplo, a UFBA é um forte polo acadêmico no desenvolvimento de atividades que envolvem essa modalidade de ensino. Um exemplo dessa contribuição é o fato de a Instituição ser um dos postos aplicadores do exame Celpe-Bras (Certificado de Proficiência em Língua Portuguesa para Estrangeiros) ${ }^{10}$, além de ofertar uma licenciatura plena em PLE desde 2005, como já apresentado. Ademais, dois cursos de português para estrangeiros são ofertados, sendo um de extensão, através do NUPEL (Núcleo Permanente de

\footnotetext{
$9 \quad$ Agradecimento a CAPES pelo financiamento da bolsa de pesquisa.

10 O Celpe-Bras é o exame oficial do governo brasileiro para a certificação de proficiência em português como língua estrangeira e foi criado em 1994. Ele é aplicado duas vezes por ano no Brasil e em diversos países no exterior. Ver: http://portal.inep.gov.br/web/guest/acoesinternacionais/celpe-bras. Acesso em: 20 ago. 2020.
} 
Extensão em Letras) $)^{11}$, além do próprio PROFICI. A pesquisa concentrou-se neste último Programa por ser uma das novas iniciativas de internacionalização da Universidade, que oferta, gratuitamente, para estudantes e servidore(a)s da UFBA, seis cursos de línguas estrangeiras (inglês, espanhol, francês, alemão, italiano e português para estrangeiros) ${ }^{12}$.

O PROEMPLE (Programa Especial de Monitoria de Português como Língua Estrangeira), um dos 6 subprogramas do PROFICI e recorte da pesquisa de Rodrigues (2019), foi instituído a partir do ano de 2014 e possibilitou que estudantes intercambistas das mais variadas parcerias ${ }^{13}$ da UFBA pudessem fazer um curso de português para estrangeiros no Brasil. Dentre esses programas parceiros, o PEC-G'14 (Programa de Estudantes-Convênio de Graduação) foi outra delimitação da referida pesquisa, uma vez que determina a seus participantes, que não tenham aplicação de Celpe-Bras em seus países, a obrigatoriedade de fazer um curso de português no Brasil, que dura em média de 6 a 8 meses $^{15}$.

$\mathrm{O}(\mathrm{a})$ estudante pré-PEC-G $\mathrm{G}^{16}$ tem por finalidade fazer uma graduação em alguma Instituição de Ensino Superior (IES) no Brasil. Para isto, alguns requisitos precisam ser cumpridos, tais como, submeter a candidatura nas embaixadas de

\footnotetext{
11 A partir da seção 4 deste artigo, a pesquisa de Cruz (2019) descreve de forma mais minuciosa o que é o referido programa de extensão.

12 O PROFICI foi implementado no segundo semestre de 2012 e conta, atualmente, com 6 (seis) subprogramas: PROEMA (alemão), PROEMES (espanhol), PROEMF (francês), PROEMI (inglês), PROEMIT (italiano), PROEMPLE (português como língua estrangeira). Através desses subprogramas, o PROFICI proporciona o atendimento aos alunos, a matrícula, a organização das turmas referentes a cada curso e promove a formação continuada dos monitores, os quais ministram as aulas. Ver: https://profici.ufba.br/. Acesso em: 21 ago. 2020.

13 Ver: https://aai.ufba.br/. Acesso em: 21 ago. 2020.

14 O PEC-G foi criado em 1965, no Brasil, e é administrado pelo Ministérios das Relações Exteriores (MRE) e pelo Ministério da Educação (MEC). O programa oferece oportunidades de formação superior a cidadãos de países em desenvolvimento com os quais o Brasil mantém acordos educacionais e culturais, dos seguintes continentes: África, Ásia, Europa, América Latina e Caribe Ver: http://portal.mec.gov.br/pec-g. Acesso em: 30 jul. 2020.

15 Ver: http://www.dce.mre.gov.br/PEC/G/2021/Edital PEC-G 2021.pdf. Acesso em: 15 ago. 2020.

16 A nomenclatura "pré-PEC-G" foi utilizada pelo pesquisador, pois os alunos só são integrados ao programa PEC-G quando fazem uma graduação no Brasil, isto é, após a realização do curso de português e a aprovação no exame Celpe-Bras.
} 
seu país, fazer um curso de português no Brasil através de uma instituição conveniada, estar de acordo com as normas do Decreto brasileiro $\mathrm{n}^{\circ} 7.948^{17}$, como ser capaz de custear suas despesas no país e apresentar proficiência em língua portuguesa (certificação obrigatória pelo Celpe-Bras). Importa ressalvar que os participantes podem ser certificados no exame Celpe-Bras nos seguintes níveis: intermediário, intermediário superior, avançado e avançado superior. Para poder realizar uma graduação no Brasil, o(a) estudante precisa alcançar o nível intermediário.

Em relação à metodologia de pesquisa, Rodrigues (2019) desenvolveu seu trabalho a partir de uma abordagem qualitativa, de cunho etnográfico, em duas etapas. Na primeira, o pesquisador realizou a observação de aulas e aplicou um questionário, e, na segunda, realizou entrevistas semiestruturadas. A investigação contou com a participação de 18 aluno(a)s de duas turmas do PROEMPLE, dos seguintes países: Benin, Congo, Gabão, Gana, Guatemala, Honduras e Mali, falantes das línguas francesa, inglesa, espanhola e de várias línguas africanas, conforme apresentado no perfil dos participantes (RODRIGUES, 2019, p.25).

A abordagem pedagógica desenvolvida no PROEMPLE, a pedagogia de projetos, é fundamentada na pedagogia ativa de ensino, proposta idealizada por John Dewey e William Kilpatrick, a qual tem por característica central proporcionar ao(à) aluno(a) um aprendizado baseado em ações práticas que estejam ligadas às demandas sociais que circundam esse indivíduo (DEWEY, 1897). Essa abordagem pedagógica tem sido utilizada em diferentes áreas do conhecimento, sobretudo na Educação. No entanto, no âmbito do ensino de línguas estrangeiras, tal corrente se desenvolveu a partir da década de 80, nos

\footnotetext{
17 Ver: http://www.planalto.gov.br/ccivil 03/ ato2011-2014/2013/decreto/d7948.htm. Acesso em: 22 jul. 2020.
} 
Estados Unidos, e foi defendida como um meio eficaz para se promover o aprendizado de idiomas, de acordo com Stoller (2006).

Rodrigues (2019) mostra que, no PROEMPLE, os diferentes projetos são estruturados por temas variados, como: "Meu amigo brasileiro", "Cinema brasileiro", "Choque cultural”, "Gincana em Salvador", “Meu país, minha raiz”, entre outros. As atividades desenvolvidas nos projetos, conforme apresenta o pesquisador, priorizam a interação e os relatos de experiências vividos pelo(a)s aluno(a)s, dentro e fora da sala de aula. Através dos dados gerados pelos questionários e entrevistas, os estudantes destacaram os pontos positivos e negativos no aprendizado com a pedagogia de projetos. Como pontos favoráveis, foi constatado que, para a maioria do(a)s aluno(a) $\mathrm{s}^{18}$, essa abordagem estimula a interação com a língua e o seu entorno social, pois parte das tarefas são realizadas em ambientes externos à sala de aula, além de incentivar a prática da oralidade. Por outro lado, os principais aspectos negativos evidenciados pelos participantes da pesquisa foram a sensação de insuficiência de aprendizagem, principalmente no que tange à abordagem gramatical, à implementação de temas que não refletiam o interesse de aprendizagem dos alunos, à ausência de orientação sobre a metodologia e à necessidade de feedback sobre as atividades escritas que eram resultantes dos projetos.

Além dos aspectos mencionados, ao confrontar os dados da pesquisa com um quadro elaborado por Stoller $(2006)^{19}$, que apresenta oito benefícios dos aprendentes dessa abordagem, o pesquisador destacou dois pontos coincidentes: melhoria do trabalho em grupo e maior autonomia na aprendizagem. De acordo com a fala do(a)s aluno(a)s, no que se refere ao trabalho em grupo, o ambiente multinível - sistema adotado no PROEMPLE por razões estruturais e financeiras - trouxe benefícios, como ajudar o(a)s colegas no processo de aprendizagem.

18 Conforme a pesquisa de Rodrigues (2019), 5\% dos alunos acharam a metodologia do curso insuficiente, $17 \%$ suficiente, $28 \%$ regular, $33 \%$ classificaram como bom e $17 \%$ como excelente.

19 Ver: STOLLER, 2006, p.25. 
Porém, muitos deles enfatizaram que isso causou uma sensação de insuficiência na aprendizagem, já ressaltado anteriormente, por conta de não terem seus anseios atendidos durante a aula, especialmente em relação a uma sistematização mais direta dos conteúdos gramaticais. Isso se opõe à ideia de melhoria mútua no trabalho em grupo. Outrossim, o pesquisador concluiu que a aparente atitude autônoma apresentada na postura de parte do(a)s aluno(a)s não se deve ao desenvolvimento das atividades dos projetos, mas sim ao fato de que os estudantes tinham a necessidade de aprender determinados conteúdos e não se sentiam atendidos em sala de aula, fazendo-os buscar fontes de aprendizagem alternativas.

Por fim, os resultados da pesquisa de Rodrigues (2019) apontaram para a necessidade de ajustes nos temas e formatos dos projetos, bem como no PROEMPLE de modo geral. Em suma, os principais pontos que necessitariam de ajustes e reformulações destacados na pesquisa foram: a) maior presença de análise linguística nos projetos; b) feedback sistemático em relação às produções do(a)s aluno(a)s (orais e escritas); c) inserção de atividades específicas para a redução de conflitos e choques culturais nos trabalhos em grupo; d) redução do número de projetos; e) orientações constantes sobre os objetivos e a metodologia do curso; f) implementação de tutorias para alunos falantes de espanhol; g) escuta sobre os temas que os alunos gostariam de discutir em sala de aula.

Esses resultados demonstraram que os planejamentos desenvolvidos no curso de PLE do PROEMPLE são, de modo geral, desenvolvidos previamente, sem a desejada participação do(a)s aluno(a)s, público-alvo do curso, nas decisões sobre a seleção dos conteúdos, temas e procedimentos pedagógicos que guiarão as experiências de ensino-aprendizagem. A inserção de mudanças no Programa deve trazer impactos positivos para as turmas subsequentes do curso, além de contribuir para o fortalecimento das iniciativas institucionais da UFBA voltadas 
para o ensino de línguas, as quais representam importantes ações de internacionalização universitária.

\section{O USO DO BLOG EM UMA PERSPECTIVA INTERCULTURAL E CRÍTICA E A FORMAÇÃO DE PROFESSORES DE PLE}

Outra pesquisa recentemente desenvolvida no PPGLinC teve como objetivo propor o blog como um ambiente favorável ao ensino de português LE/L2 em uma perspectiva intercultural e crítica (CRUZ, 2019). Para tanto, um conjunto de atividades ${ }^{20}$ foi implementado pelo(a)s participantes da pesquisa, professore(a)s em formação que atuavam no Núcleo Permanente de Extensão em Letras (NUPEL) ${ }^{21}$ ou no Programa Especial de Monitoria de Português como Língua Estrangeira (PROEMPLE) ${ }^{22}$. Essas atividades, de acordo com Cruz (2019), poderiam potencializar o uso do blog em uma perspectiva sensível à cultura dos sujeitos envolvidos no processo de ensino-aprendizagem, consoante Mendes (2004, 2011, 2012b), e desencadear experiências interculturais, ou seja, possibilitar o diálogo entre os diferentes e sobre as diferenças.

Segundo Cruz (2019, p. 51), o curso de PLE ofertado no NUPEL destina-se tanto a estrangeiros recém-chegados ao Brasil, sem qualquer conhecimento da língua portuguesa, quanto àqueles que já são capazes de se comunicar em português e queiram aperfeiçoar a sua proficiência oral e escrita. No período em

\footnotetext{
20 O conjunto de atividades foi dividido em três Unidades Temáticas: "Como é a sua Rotina", "Preconceito" e "Racismo", que resultaram das observações de aulas dos professores em formação participantes da pesquisa e de produções textuais de alunos de língua estrangeira.

21 O NUPEL (Núcleo Permanente de Extensão em Letras), criado em 2012, é o órgão responsável pela coordenação, fomento, gerenciamento, apoio, acompanhamento e avaliação de ações de extensão que se enquadrem nas diretrizes conceituais, políticas, educacionais e legais estabelecidas pelo Estatuto, pelo Regimento Geral e pelo Regulamento de Extensão da UFBA. Nesse Núcleo são oferecidos cursos de Línguas Estrangeiras Modernas (Alemão, Espanhol, Francês, Inglês e Italiano) e Clássicas (Grego e Latim), além de cursos de Língua Portuguesa (Leitura e Produção de Texto), Português Língua Estrangeira e Língua Brasileira de Sinais LIBRAS. Fonte: http://www.letras.ufba.br/extensao. Acesso em: 13 ago. 2020

22 A pesquisa anteriormente apresentada (RODRIGUES, 2019) também teve como cenário o PROEMPLE, subprograma do PROFICI.
} 
que foi realizada a pesquisa, o Núcleo contava com dois professore(a)s em formação e uma coordenadora. As aulas eram ministradas por estudantes da graduação e da pós-graduação stricto sensu do Instituto de Letras, aprovado(a)s através de Edital. $\mathrm{O}(\mathrm{A})$ estudante selecionado(a) poderia permanecer no Núcleo no tempo máximo de 4 semestres, período de duração da bolsa concedida.

Já o curso de PLE ofertado pelo PROEMPLE destina-se a estudantes estrangeiros com matrícula regular em nível de graduação e pós-graduação e cidadãos(ãs) de países em desenvolvimento com os quais o Brasil mantém acordos educacionais e culturais (países da Ásia, África, América Latina e Caribe) que fazem parte do PEC-G, como já apontou a pesquisa de Rodrigues (2019). Em relação ao(à)s estudantes regularmente matriculado(a)s em nível de graduação, estes estão conveniados à UFBA através da Assessoria para Assuntos Internacionais (AAI); já os estudantes estrangeiros da pós-graduação estão conveniados à Universidade através da PAEC - OEA (Programa de Parcerias para Educação e Treinamento - Organização dos Estados Americanos). ${ }^{23}$

Embora a pesquisa de Cruz (2019), inicialmente, tenha se debruçado na investigação sobre as potencialidades de uma ferramenta pedagógica, o blog, no ensino de PLE, tomando como cenário da pesquisa dois projetos institucionais da UFBA, à medida que a sua investigação avançava, a autora percebeu a necessidade de redimensionar os seus objetivos, de modo a incluir um olhar mais aprofundado sobre o próprio funcionamento dos projetos em tela (PROEMPLE e NUPEL) e os modos como o(a)s professore(a)s estavam sendo formados e orientados em sua prática.

Com esse entendimento, Cruz (2019) verificou que uma parte dos professores em formação, 37,5\%, recebeu, inicialmente, orientação das coordenações dos programas em relação ao planejamento do cronograma e/ou dos planos de aulas, enquanto a outra parte, $62,5 \%$, não recebeu orientação que

23 Rodrigues (2019), em sua pesquisa, identifica-os como estudantes intercambistas. 
contribuísse com os planejamentos de suas aulas, tendo, portanto, os seus planejamentos influenciados, sobretudo, pelo que demandavam os alunos dos cursos de PLE.

Para a pesquisadora, essa demanda nem sempre condiz com uma aprendizagem significativa, já que tendências contemporâneas de ensinoaprendizagem de línguas apresentam abordagens/perspectivas que vão de encontro ao ensino tradicional, no qual o ensino da gramática ocupa lugar central. Assim, é fundamental que os professores em formação sejam (continuamente) preparados a refletir sobre as concepções que têm orientado a prática docente, pois a ausência de uma orientação em contextos formativos pode reforçar práticas tradicionais do ensino de línguas.

Cruz (2019) ressalta que, em um ensino de língua em perspectiva intercultural, a participação dos aprendizes na elaboração do curso, dando sugestões do que querem aprender, por exemplo, é fundamental; no entanto, precisamos estar atentos para aquilo que compete ao professor: decidir como e quando os conteúdos/temas, por exemplo, serão trabalhados/abordados no curso, procurando escolher instrumentos, procedimentos, abordagens que contribuam na aprendizagem.

Os dados da referida pesquisa foram gerados a partir das observações de aulas e entrevistas realizadas com todo(a)s o(a)s participantes; da implementação do conjunto de atividades e também dos relatórios de estágio do(a)s professore(a)s em formação. Cruz (2019) analisou também registros ${ }^{24}$ do início da sua atuação docente, como professora em formação no NUPEL, a fim de identificar de que modo suas próprias experiências foram ressignificadas a partir do desenvolvimento da investigação.

24 E-mails, um artigo apresentado em um dos Congressos Internacionais da SIPLE, produções escritas dos ex-alunos e o blog Vivendo no Brasil. 
Com base no objetivo geral proposto no estudo de Cruz (2019), só é possível potencializar o uso do blog nas aulas de PLE como um ambiente favorável ao ensino em uma perspectiva intercultural e crítica se o trabalho com essa ferramenta digital for resultado de um conjunto de ações que envolve professore(a)s formadore(a)s, professor(a) em formação, aprendizes e sociedade. Ou seja, se as postagens publicadas do(a)s aluno(a)s no blog forem motivadas por um planejamento sensível, cabendo ao(à) professor(a) o papel de orientar as produções do(a)s seus/suas aluno(a)s, divulgá-las na rede, a fim de alcançar um público leitor que se sinta motivado a interagir com os aprendizes da línguacultura que aprendem.

Nesse sentido, a autora compreende que essas ações podem motivar aluno(a)s e professore(a)s a tornar o processo de ensino-aprendizagem mais rico e significativo, além de ressignificar o uso de blog nas aulas de PLE/L2, o qual tem servido apenas como um repositório de textos e informações descontextualizadas. Adicionalmente, também podem contribuir para a formação de professore(a)s mais reflexivos, mais sensíveis às práticas pedagógicas desenvolvidas em sala de aula, assim como Cruz (2019) ressaltou a contribuição dessas orientações para a sua formação como professora. Desse modo, por meio da investigação, a pesquisadora conseguiu mostrar como as produções do(a)s nosso(a)s estudantes de PLE devem ser exploradas em sala de aula, reforçando a reflexão de que professore(a)s e aluno(a)s necessitam repensar a língua ao longo do processo de ensino-aprendizagem, analisando-a a partir de insumos que são produzidos na própria interação.

Para efeito da discussão realizada neste capítulo, o que ficou bastante evidente no trabalho de Cruz (2019) foi a defesa de uma orientação teóricopedagógica mais ativa, simétrica (e mais significativa) para o(a)s professore(a)s em formação, capaz de promover a reflexividade crítica (LIBÂNEO, 2006) durante toda a licenciatura de PLE, a fim de que se formem professore(a)s 
críticos-reflexivos, sabedore(a)s das concepções, das crenças e das abordagens que orientam a sua prática pedagógica, além da seleção e produção de materiais didáticos e de instrumentos de avaliação, entre outros.

Tal defesa se deu porque Cruz (2019) identificou uma assimetria na formação desses profissionais, que, em sua maioria, segundo a investigação, estão sendo expostos a problemas, situações e conflitos que surgem nas interações entre sujeitos culturalmente diferentes, os quais vão além de aspectos puramente linguísticos. Segundo ela, isso tem tido um grande significado no curso de Letras em foco, e esse tipo de orientação, portanto, deve estar presente na estrutura geral do curso e não deve depender das abordagens individuais do(a)s professore(a)s formadore(a)s, como demonstraram os dados da sua pesquisa.

Na perspectiva da pesquisadora, o(a)s professore(a)s em formação deveriam ser (continuamente) preparado(a)s a refletir sobre as concepções que têm orientado a sua prática docente, pois a ausência de uma orientação em contextos formativos pode estar reforçando práticas tradicionais do campo do ensino de línguas. Isso entraria em choque com a proposta formativa do Curso de Letras, que, além de prepará-los(las) para a abordagem de conteúdos específicos da língua, visa formar professore(a)s de línguas capazes de formar cidadã(o)s plurilingues e interculturais, tal como discutido na primeira parte deste capítulo. Logo, uma adequada orientação teórico-pedagógica deve estar imbricada de modo orgânico ao planejamento das aulas e ao currículo da licenciatura de PLE, com o objetivo de ajudar o(a)s professore(a)s em formação a antever e/ou identificar as necessidades do(a)s estudantes de PLE e os possíveis conflitos linguístico-culturais vivenciados por todo(a)s eles/elas nas interações em sala de aula, além de tornar as aulas de PLE um lugar para o desenvolvimento de práticas interculturais no processo de aprender e ensinar línguas. 


\section{CONSIDERAÇÕES FINAIS}

Um dos pontos positivos do processo acelerado de desenvolvimento do português, sobretudo em contexto de PLE/PL2, é que o crescente interesse e a forte demanda por um ensino de qualidade, com materiais de qualidade e a partir de abordagens contemporâneas para o ensino/aprendizagem de línguas têm forçado as instituições a buscarem novos caminhos para a formação de corpo qualificado e capaz de atender à grande demanda do mercado, não só no Brasil, mas em todas as partes do mundo. Entre outros aspectos, elas têm sido obrigadas a rever os velhos esquemas de curso e os currículos enrijecidos e retrógrados dos cursos de Letras, para refletirem sobre questões importantes e relevantes para o(a) professor(a) contemporâneo(a), como, por exemplo, sobre visões de língua e de linguagem menos sistêmicas e mais sensíveis culturalmente, como apontam as pesquisas de Rodrigues (2019) e Cruz (2019). Nesse sentido, a área de formação de PLE da UFBA deve reforçar a formação humana e intercultural do(a)s professore(a)s, com o objetivo de prepará-lo(a)s para atuar em contextos complexos e multilíngues, marcados pela diversidade, pela desigualdade e, muitas vezes, pela injustiça social.

A pesquisa de Rodrigues (2019) demonstrou que a abordagem pedagógica do PROEMPLE, a pedagogia de projetos, apresenta lacunas importantes para o processo de aprendizagem do(a)s aluno(a)s em uma língua estrangeira, principalmente em um ambiente multinível, como o que foi investigado. Conforme o pesquisador, programas bem estruturados e com boa avaliação não trazem benefícios apenas para seus/suas estudantes e professore(a)s em formação. As ações que são empreendidas dentro de programas institucionais, como o PROEMPLE, são de suma importância também para o fortalecimento das políticas linguísticas implementadas pela Universidade, dando-lhe maior 
visibilidade em âmbito internacional, através da manutenção e do incremento de suas parcerias.

Por sua vez, a investigação empreendida por Cruz (2019) evidencia a necessidade de um diálogo mais consolidado entre o(a)s professore(a)s formadore(a)s da área de PLE da UFBA, que atuam em diferentes setores da Licenciatura, a fim de ampliar as visões do(a)s professore(a)s em formação sobre as diferentes dimensões que integram o processo de ensinar e aprender línguas, dando-lhes a oportunidade de conhecer as diferentes formas de compreender a língua e o seu ensino. Além disso, a pesquisa mostrou que ferramentas digitais como o blog podem ser potencializadoras de práticas pedagógicas mais dinâmicas e contextualizadas à vida contemporânea, contribuindo para o uso em sala de aula de materiais didáticos interculturais e sensíveis às pessoas envolvidas nos processos de interação, dentro e fora da sala de aula.

Dessa forma, as pesquisas de Cruz (2019) e Rodrigues (2019) demonstram a necessidade de ajustes nos projetos institucionais da UFBA, sobretudo na área de PLE, notadamente o PROEMPLE e o NUPEL, como meio de fortalecimento do ensino e da formação de professore(a)s, dando visibilidade à Universidade, no Brasil e no exterior, contribuindo diretamente para o processo de internacionalização universitária.

Finalmente, a ampliação da oferta do português como língua estrangeira e da formação de novo(a)s professore(a)s tem exigido das instituições educativas, especialmente das universidades, a alocação de recursos para o desenvolvimento de projetos de criação de novos cursos em nível de graduação e de pós-graduação na área, bem como de iniciativas para a formação de professore(a)s em serviço. Nos próximos anos, muitos resultados dessa efervescência serão evidentes, como uma grande quantidade de novos materiais no mercado, o grande contingente de professore(a)s formados e em contínuo processo de capacitação, a criação de 
cursos e de recursos em ambiente virtual, para o acesso de toda a comunidade PLE/PL2.

Uma formação em nível superior, portanto, deve preparar o(a) professor(a) de PLE/PL2 para agir na diversidade, sendo capaz de compreender os fenômenos mais amplos da globalização como inevitáveis e profundamente determinantes dos comportamentos sociais e, consequentemente, interacionais, e que vão afetar o seu ambiente educacional, em maior ou menor escala. Uma formação para a diversidade que seja capaz de fazer o(a) professor(a) compreender que a língua que ensina não deve ser fator de discriminação e de exclusão de outros povos e línguas, mas de sua preservação e proteção. Finalmente, uma formação adequada deve dar ao(à) professor(a) ferramentas para lidar com a adversidade, a discriminação, a exclusão social, que afetam seriamente muitas salas de aula de línguas, realidade cada vez mais frequente em relação ao português, nos diferentes cantos do mundo. A UFBA, nesse sentido, vem cumprido o seu papel na institucionalização da área, sendo atualmente uma das maiores referências no Brasil, e também no exterior, no ensino e na formação de professore(a)s de PLE/PL2.

\section{REFERÊNCIAS}

CRUZ, S. O. da. Fiz um blog, e daí? Uma experiência sobre o ensino e a formação inicial de professores de português como língua estrangeiralsegunda língua em perspectiva intercultural e crítica. 263 f. 2019. Dissertação (Mestrado) - Programa de Pós-Graduação em Língua e Cultura, Instituto de Letras, Universidade Federal da Bahia, Salvador, 2019.

DEWEY, John. My pedagogic creed. School Journal. Vol. 54.1897. p. 77 -80. Disponível em:< http://dewey.pragmatism.org/creed.htm>. Acesso em: 29 de setembro de 2017.

LIBÂNEO, José Carlos. Democratização da Escola Pública: a pedagogia crítico-social dos conteúdos. 21aㅡ ed. São Paulo: Loyola, 2006.

MENDES, Edleise. Abordagem Comunicativa Intercultural (ACIN): uma proposta para ensinar e aprender língua no diálogo de culturas. Campinas, SP: [s.n.], 2004. Disponível em: $<$ http://repositorio.unicamp.br/jspui/handle/REPOSIP/269430>. Acesso em: 26 out. 2018. 
MENDES, Edleise. Língua, cultura e formação de professores: por uma abordagem de ensino intercultural. In: Mendes, Edleise; Castro, M. L. S. (Org.) Saberes em português: ensino e formação docente. Campinas/SP: Pontes, 2008. 57-77.

MENDES, Edleise. O português como língua de mediação cultural: por uma formação intercultural de professores e alunos de PLE. In: MENDES, E. (Org.) Diálogos Interculturais: ensino e formação em português língua estrangeira. Campinas, SP: Pontes Editores, 2011.

MENDES, Edleise. O conceito de língua em perspectiva histórica: reflexos no ensino e na formação de professores de português. In: LOBO, Tânia et alii. Linguística histórica, história das línguas e outras histórias. Salvador-BA: EDUFBA, 2012a.

MENDES, Edleise. Aprender a ser e a viver com o outro: materiais didáticos interculturais para o ensino de Português LE/L2. In: SCHEYERL, D.; SIQUEIRA, S. Materiais didáticos para o ensino de línguas na contemporaneidade: contestações e proposições. Salvador: EDUFBA, 2012b.

MENDES, Edleise. Formar professores de português LE/L2 na universidade: desafios e projeções. In: KANEOYA, Marta Lúcia C. K. Português língua estrangeira em contextos universitários: experiências de ensino e de formação docente. Campinas-SP: Mercado de Letras, 2018.

MENDES, Edleise. A promoção do português como língua global no século XXI. Linha D'Água, 32(2), 37-64. 2019. Disponível em: https://doi.org/10.11606/issn.22364242.v32i2p37-64. Acesso em 23 julho 2020.

MENDES, Edleise. A Licenciatura em PLE/PL2 na Universidade Federal da Bahia: formando professores para a diversidade. In: SCARAMUCCI, Matilde; BIZON, Ana Cecília C.. (Org.). Formação inicial e continuada de professores de Português Língua Estrangeira / Segunda Língua no Brasil. 1. ed. Araraquara/SP: Letraria, 2020, v. 1, p. 41-62.

RODRIGUES, Lucas. Uma experiência de aprendizagem com o português LE/L2 na BahiaBrasil: percepções dos aprendentes pré-PEC-G (UFBA) sobre a pedagogia de projetos. (Dissertação) Mestrado em Língua e Cultura. Universidade Federal da Bahia, Salvador, 2019.

STOLLER, Fredika. Establishing a theoretical foundation for project-based learning in second and foreign language contexts. In: Project Based Second and Foreing Language Education. Universidade do Norte do Arizona, 2006. p.19-46.

\section{OS AUTORES E O PPGLinC}

\section{Lucas Rodrigues}

É mestre em Língua e Cultura pelo PPGLINC (Programa de Pós-Graduação em Língua e Cultura) da Universidade Federal da Bahia. Além disso, possui graduação em Letras Vernáculas e Letras Vernáculas com Língua Estrangeira, com ênfase em PLE (Português Língua Estrangeira) pela mesma instituição. No 
desenvolvimento de sua dissertação, Rodrigues buscou investigar as percepções de aprendizagem de alunos pré-PEC-G participantes de um programa institucional da UFBA, a saber o PROFICI (Programa de Proficiência para Estudantes e Servidores da UFBA). A sua formação no PPGLINC foi de suma importância para seu trabalho, uma vez que contribuiu para a fundamentação das discussões realizadas em sua pesquisa. Atualmente, é professor da área de português como língua estrangeira e integrante do grupo de pesquisa LINCE (Núcleo de Estudos em Língua Cultura e Ensino).

\section{Sara Oliveira da Cruz}

É graduada em Letras Vernáculas e Português como Língua Estrangeira, especialista em Educação a Distância e mestra em Língua e Cultura, na área de Linguística Aplicada, pela UFBA. Sua pesquisa versa sobre ensino e formação de professores de português como língua estrangeira/segunda língua e abordagens interculturais e críticas para o ensino de línguas. A formação adquirida no Programa de Pós-Graduação em Língua e Cultura (PPGLinC) contribuiu significativamente para a sua atuação como professora-pesquisadora-crítica. Atualmente, é professora substituta de Língua Portuguesa do IFBA e pesquisadora no Núcleo de Estudos em Língua, Cultura e Ensino (LINCE/CNPQ) e no Observatório de Português Língua Estrangeira/Segunda Língua (ObsPLE-PL2, CNPQ). Tem atuado, desde 2012, no Exame de Certificação de Proficiência em Língua Portuguesa para Estrangeiros (CELPE-BRAS).

\section{Edleise Mendes}

É mestre em Estudos Linguísticos (Universidade Federal da Bahia-UFBA, 1996), doutora em Linguística Aplicada (Universidade Estadual de CampinasUNICAMP, 2004) e Pós-Doutora em Educação e Ciências Sociais (Centro de Estudos Sociais - CES), na Universidade de Coimbra, Portugal (2014) e na Universidade Estatal das Humanidades de Moscou (RGGU), em Moscou, Rússia (2019/2020). Atualmente é professora associada da Universidade Federal da Bahia (UFBA), onde atua na graduação e no Programa de Pós-Graduação em Língua e Cultura (PPGLinC). Dedica-se a estudos sobre a língua portuguesa, materna e estrangeira (em seus variados contextos) e à área da educação linguística de modo geral, com enfoque na formação de professores de línguas, avaliação e produção de materiais didáticos, abordagens interculturais e críticas para o ensino de línguas.

Nota do editor:

Artigo submetido para avaliação em: 04 de outubro de 2020.

Aprovado em sistema duplo cego em: 18 de fevereiro de 2021. 